\title{
Analysis of South Hemisphere Temperature Anomalies over the Last Millennium up to the Beginning of the Contemporary Age: A Comparison between a Statistical Model and a Global Dynamic Model
}

\author{
Gabriela V. Müller, Cintia R. Repinaldo \\ Centro de Investigaciones Científicas y Transferencia de Tecnología a la Producción (CICYTTP-CONICET) \\ Diamante, Entre Ríos, Argentina \\ Email: gabrielamuller@cicyttp.org.ar, cintia.rabelo@cicyttp.org.ar
}

Received 12 February 2014; revised 8 March 2014; accepted 1 April 2014

Copyright (C) 2014 by authors and Scientific Research Publishing Inc.

This work is licensed under the Creative Commons Attribution International License (CC BY). http://creativecommons.org/licenses/by/4.0/

(c) (i) Open Access

\section{Abstract}

We analyze the consistency of the coupled atmosphere-ocean GISS-ER climate model in reproducing South American temperature anomalies over the last millennium. For that purpose, we compare the model results with the Neukom's temperature anomaly reconstruction provided by a statistical model that uses multiproxy data and climatological temperature anomalies. Specifically, we examine temperature anomalies for summer and winter of a 6-member ensemble of the GISS-ER model with $1 \times$ solar forcing and $2 \times$ solar forcing, calculated for the period 1000-1899. Using the Neukom's reconstructions and the model outputs, we calculate the summer mean anomalies of the period 1001-1700 (a period that includes Medieval Climate Anomaly -MCA- and Little Ice Age -LIA-), and winter mean anomalies of the period 1706-1800 (a period that includes the pre-industrial period). These mean anomalies are subtracted from Neukom's reconstructions defining the reconstructions wrt 1001-1700 (summer) and wrt 1706-1800 (summer and winter). In general, the model is not very consistent with the reconstructions, since the model's mean and spread show very small interannual variability in contrast to what the reconstructions exhibit, and often with anomalies of opposite sign. In the period 1001-1700, the model presents, on average, negative temperature anomalies for the $1 \times$ and $2 \times$ forcing. In the period 1706-1800, the model displays positive anomalies for summer and negative anomalies for winter for the $1 \times$ and $2 \times$ forcing. In particular, the anomaly that better reproduces the sign of the reconstructions is that wrt 1001-1700 with $1 \times$ forcing and for summer. The model has an error of only $33 \%$ in reproducing the sign of the anomalies, in comparison to the Neukom's reconstruction for the same refer- 
ence period. The model's anomaly wrt 1001-1700 with $1 \times$ forcing for summer also reproduces the MCA and LIA's sign of the reconstruction. The MCA's sign is reproduced in almost $75 \%$ of the comparisons, and the LIA's sign in more than $73 \%$ of the comparisons with the reconstruction, indicating that the model can represent this important anomalies.

\section{Keywords}

\section{Temperature Reconstruction, Climate Models, Solar Forcing, MCA, LIA}

\section{Introduction}

In the last 1500 years, global temperatures varied by a few tenths of a degree, although the patterns of these temperature fluctuations remain uncertain in detail. However, considerable progress has been made in using climate "proxy" data to reconstruct large-scale trends in past centuries [1], and in using climate models to assess the role of natural and anthropogenic forcing in those trends [1]. Several temperature climate reconstructions of the past thousand years have been published, using data from various sources including documentary evidence, tree rings, ice cores, corals, lake sediments and borehole data, and others, as proxies using statistical calibration methods (i.e. [2]-[13]). The reconstructions of temperature indices or fields allow climate variability estimates prior to widespread availability of instrumental records, validation fields for general circulation models (GCMs), and estimates of climate sensitivity that help constrain climate projections for the 21st century [14].

Several variables may have contributed to the observed changes, such as internal variations of the climate system itself, or external drivers such as solar and volcanic activity [15], and more recently, human activity [16]. In particular Mann et al. [1], use the solar forcing paleoclimatic simulations of the coupled atmosphere-ocean GISS-ER climate model of NASA Goddard Institute for Space Studies (GISS), and compare them with global climate proxy network to reconstruct surface temperature patterns over the past fifteen hundred years. They performed six GISS-ER climate model simulations are employed with $1 \times$ and $2 \times$ solar forcing. Mann et al. [1] show that the temperature anomaly reconstruction of the MCA (Medieval Climate Anomaly, defined as 1001-1350 by [17]) and the LIA (Little Ice Age), defined as 1400-1700 by [17], are more reliable over the Northern Hemisphere and the tropics, and less reliable over the Southern Hemisphere, particularly in the extratropics. These results could be due the oceanic characteristics of the Southern Hemisphere and the limited number of proxies available over land. For example, [1] use only three proxies for the MCA and none for the LIA in South America. Therefore the question that arises is, which would be the result of a reconstruction that considers several proxies in the South American continent. Neukom et al. [11] made a reconstruction that includes multiproxy measurements of tree rings, lake sediment, instrumental and documental for summer (DJF); tree rings, instrumental and documental, for winter (JJA); and records that serve as a surrogate for instrumental measurements, allowing climate variations to be evaluated over the past centuries up to millennia. We compare Neukom's reconstructions of surface temperature anomalies with those obtained by using a 6-member ensemble of the model GISS-ER driven by solar forcing for the period 1000-1899.

Our interest is to determine whether the solar variations can explain variations in the reconstructions or are there other forcings, such as volcanic activity, that may have more influence in this part of the world. Therefore, we analyze the consistency of the coupled atmosphere-ocean GISS-ER climate model in reproducing South American temperature anomalies over the last millennium and in particular during three well-defined periods: MCA, LIA and the pre-industrial period. These periods have been widely studied in the Northern Hemisphere, but not much is known about them in the Southern Hemisphere, where the essentially oceanic condition and the lack of proxy data make this a complex matter. By means of a reconstruction based on proxy data and the outputs of a model forced by only solar irradiance variations, the temperature of those periods is analyzed in South America.

\section{Data and Methods}

The experiments used to analyze the temperature anomalies in the last millennium are the simulations of the climate response to solar variations obtained with the NASA-GISS modelE atmospheric GCM [18] coupled to 
the Hybrid Coordinate Ocean Model (HYCOM) fully dynamic ocean [19]. The atmospheric model includes fully interactive atmospheric chemistry extending from the surface to the lower mesosphere [20]. The model also includes the ozone response to solar irradiance variations, which is parameterized for computational efficiency based on the results of prior GISS modeling using a full atmospheric chemistry simulation ([1] [20]). The configuration used has a horizontal resolution of $4 \times 5$ degrees (latitude by longitude), with 23 vertical layers in the atmosphere, and including a gravity wave drag (GWD) parameterization in the stratosphere. The dynamic ocean model HYCOM includes 16 vertical layers with horizontal resolution of $2 \times 2$ degrees, and produces a reasonable magnitude of El Niño-Southern Oscillation (ENSO)-like variability [21].

A total of six climate simulations with the coupled atmosphere-ocean climate model GISS-ER [22] were performed considering a region located between $20^{\circ} \mathrm{S}-65^{\circ} \mathrm{S}$ and $27.5^{\circ} \mathrm{W}-82.5^{\circ} \mathrm{W}$, an area that coincides with that used in Neukom reconstruction [11]. Following a control run to establish stable initial conditions, six transient runs extending from 850 to 1900 of the Common Era were performed. Solar forcing was applied across the ultraviolet, visible and infrared spectrum based on scaling by wavelength versus total irradiance as seen in modern satellite data [23]. The total irradiance through time was based on the time series of [24], derived from South Pole ice core ${ }^{10} \mathrm{Be}$ data and taking into account a small long-term geomagnetic modulation and a polar enhancement factor. The amplitude is scaled to give a top-of-the-atmosphere forcing of $1.1 \mathrm{~W} / \mathrm{m}^{2}$ between the Maunder Minimum and the late 20th century, with a second ensemble using twice that amplitude to test sensitivity. We name these experiments as $1 \times$ and $2 \times$ solar forcing.

Neukom et al. [11], using climatological values of temperature anomalies and multiproxy data for the calibration, made the reconstruction with respect to (wrt) the mean value 1901-1995. This Neukom reconstruction serves as a basis for our reconstructions wrt 1001-1700 for summer and wrt 1706-1800 for winter, because it is the period when Neukom starts for these seasons. The mean value of the temperature anomalies of the period 1001-1700 is subtracted from the Neukom summer reconstruction, defining the summer reconstruction wrt 1001-1700. The mean value of the temperature anomalies of the period 1706-1800 is subtracted from Neukom reconstruction, defining the summer and winter reconstructions wrt 1706-1800. In particular for summer, the aim is to determine if there are differences between the results for both reference periods in which the pre-industrial period is included. A simple 10-year moving average is applied to the time series of annual temperature anomalies for both periods. We also calculate the standard deviation of the temperature anomalies based on the respective reference periods, as well as the percentage of years in which the model temperature anomalies are greater and smaller than those of the reconstructions. In summary, we focus on two specific reference periods for which proxy data reconstructions are available, i.e., 1001-1700 for summer and 1706-1800 for summer and winter. The first one includes the MCA and LIA while the second one includes the pre-industrial period. Anomalies with respect to these periods are named as the reconstruction wrt 1001-1700 (summer), the reconstruction wrt 1706-1800 (summer and winter), the 6-member model mean wrt 1001-1700 (summer, $1 \times$ and $2 \times$ solar forcing), and the 6-member model mean wrt 1706-1800 (summer and winter, $1 \times$ and $2 \times$ solar forcing).

\section{Results and Discussions}

\subsection{Comparisons between Model and Reconstruction for the Summer Season}

In the case of the anomalies wrt 1001-1700, the model with $1 \times$ forcing (Figure 1) generally represents in a satisfactory manner the sign of the anomalies, with opposite sign in only about $33 \%$ of the comparisons, when decadal means are considered, although for all the cases the reconstruction shows greater amplitudes than the model. The mean difference between the reconstruction and model is of approximately $0.2^{\circ} \mathrm{C}$. The standard deviation of the model is about $0.06^{\circ} \mathrm{C}$. The maximum difference between the model and the reconstruction is of around $0.65^{\circ} \mathrm{C}$, and occurs in 1083 . The most important example is the period between 1647 and 1708 , which is included in the "Maunder Minimum" [25]. The "Maunder Minimum" is a period between 1645 and 1715, when sunspots were very rare, which represents a minimum in the solar activity.

When decadal averages are considered, the model with $2 \times$ forcing (figure not shown) presents opposite sign in comparison to the reconstructions in about $43.8 \%$ of the cases. The mean difference between the model and the reconstruction is approximately $0.2^{\circ} \mathrm{C}$, and the maximum difference is of around $0.6^{\circ} \mathrm{C}$ and occurred in 1400 . There are several periods with differences never larger than $0.2^{\circ} \mathrm{C}$, for example 1004-1048, 1205-1252, 1345-1388, 1504-1547, and 1664-1712.

A similar analysis, but for the anomalies wrt $1706-1800$, is made for the model with $1 \times$ forcing and the recon- 


\section{1x summer 10-year moving averages}

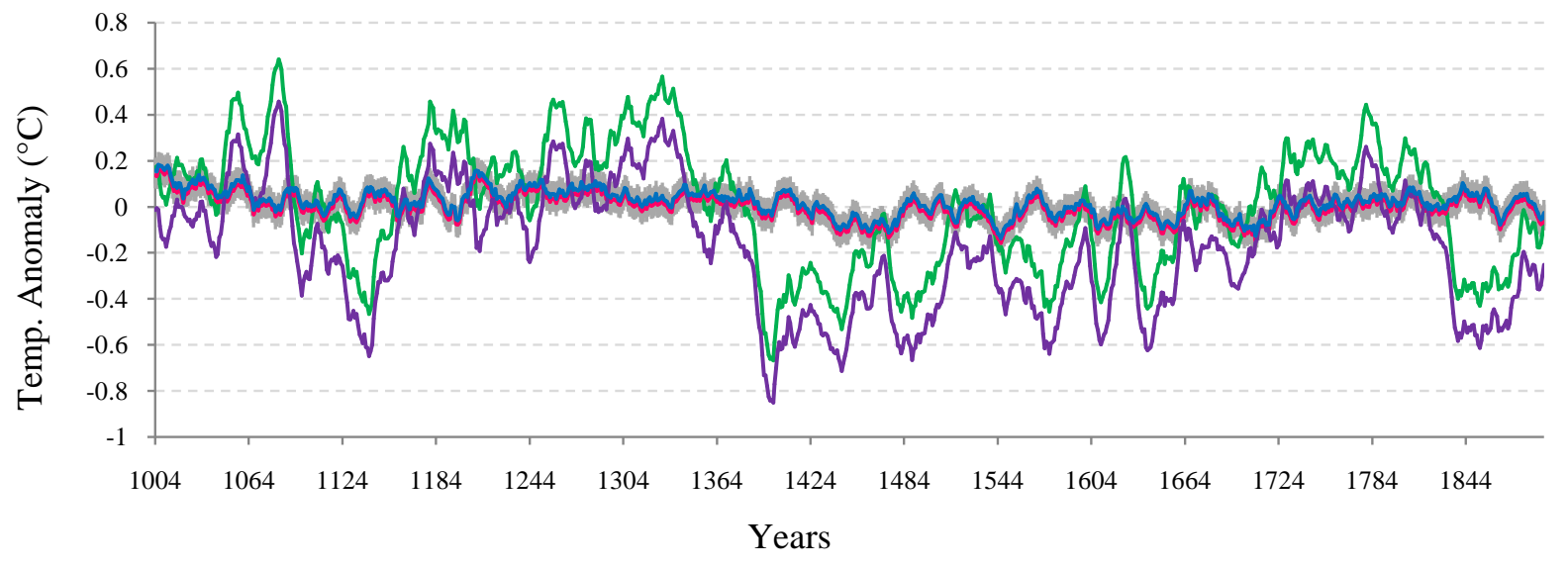

— Rec wrt 1001-1700 — Ens wrt 1001-1700 — Rec wrt 1706-1800 — Ens wrt 1706-1800

Figure 1. Temperature anomaly, 10-year moving averages, $1 \times$ forcing, summer. Green line corresponds to reconstruction wrt 1001-1700, pink line corresponds to the model 6-member mean wrt 1001-1700, purple line corresponds to the reconstruction wrt 1706-1800, and blue line corresponds to the model 6-member mean wrt 1706-1800. Shaded area indicates the model standard deviation.

structions. In this case, the sign of the anomalies is not so well represented by the model, since $46 \%$ of the comparisons show opposite sign when decadal averages are considered. Besides, the model presents $77 \%$ more cases with positive sign anomalies in comparison to the reconstruction. The mean difference between reconstruction and model is approximately $0.25^{\circ} \mathrm{C}$. The maximum difference between the model and the reconstruction occurs in 1400 and it is around $0.84^{\circ} \mathrm{C}$. Despite these major differences between the model and the reconstruction, there is a period between 1705 and 1822 when the two are very close, except in rare and isolated cases when the magnitude of the difference is greater than $0.2^{\circ} \mathrm{C}$, with few cases greater than $0.1^{\circ} \mathrm{C}$.

The sign of the anomaly is not so well represented by the model with $2 \times$ forcing (figure not shown), since it is missed in almost $47 \%$ of the cases when comparing decadal averages. However, in the case of $2 \times$ forcing, the model overestimates the amount of positive anomalies in almost $78 \%$ of the comparisons. The mean difference between the model and the reconstruction is approximately $0.26^{\circ} \mathrm{C}$, with a maximum difference of around $0.81^{\circ} \mathrm{C}$ that takes place in 1400 . The model presents some extended periods of agreement with the reconstruction, such as 1171-1209, 1703-1778, and 1784-1827.

\subsection{MCA and LIA}

In the case of MCA (Figure 2) the sign of the anomalies wrt 1001-1700 reproduced by the model with $1 \times$ forcing are consistent with the reconstruction in $74 \%$ of the comparisons, although they are underestimated in magnitude in $75 \%$ of them. Notwithstanding that, the model presents some extended periods consistent with the reconstruction, with differences of only $0.2^{\circ} \mathrm{C}$. For example, between 1004 and 1048, between 1091 and 1126, and between 1205 and 1252 that in only two occasions the difference between model and reconstruction exceeded that limit. During the LIA (Figure 2), the model also represents very well the sign of the anomalies, i.e., approximately $73 \%$ of the cases, but presents more positive anomalies than the reconstruction in about $79 \%$ of the cases. Despite this, the mean difference between the model and the reconstruction is about $0.3^{\circ} \mathrm{C}$ lower than during the MCA, i.e. around $0.19^{\circ} \mathrm{C}$.

The model with $2 \times$ forcing (figure not shown) reproduces the sign of the anomalies in $65 \%$ of the cases during the MCA, although they are underestimated in $75 \%$ of the cases. Despite this, the model presents some extended periods of agreement with the reconstruction, differing in less than $0.2^{\circ} \mathrm{C}$, for example between 1004 and 1048 and between 1205 and 1252. During the LIA, the model with $2 \times$ forcing (figure not shown) represents the sign of the anomalies in approximately $66 \%$ of cases, but although their amplitude is always smaller, the model presents more positive anomalies in comparison to the reconstruction in $73 \%$ of the cases. Despite this, the mean difference between model and reconstruction is about $0.2^{\circ} \mathrm{C}$ smaller than during the MCA, i.e. around $0.20^{\circ} \mathrm{C}$. 
During the LIA there are some extended periods when the model is really close the reconstruction, with a difference of less than $0.2^{\circ} \mathrm{C}$, being the most important one the period between 1504 and 1547. In the period between 1645 to 1700 , there are only three occasions when the difference between the model and the reconstruction is larger than $0.2^{\circ} \mathrm{C}$, i.e. 1661,1662 and 1663 .

\subsection{Comparisons between Model and Reconstruction for the Winter Season}

In the case of the anomalies wrt 1706-1800, the model with $1 \times$ forcing for the winter (Figure 3 ) shows opposite sign to the reconstruction in 54\% of the comparisons. In the period 1710-1777, the difference between the model and the reconstruction is greater than $0.2^{\circ} \mathrm{C}$ in only four occasions, i.e., $1750,1751,1765$ and 1772 . The average difference between the model and the reconstruction is approximately $0.2^{\circ} \mathrm{C}$, with a maximum of $0.7^{\circ} \mathrm{C}$ in 1814 . The model presents opposite sign to the reconstruction in $54 \%$ of the comparisons, in the case of $2 \times$ forcing

\section{1x summer: MCA and LIA}

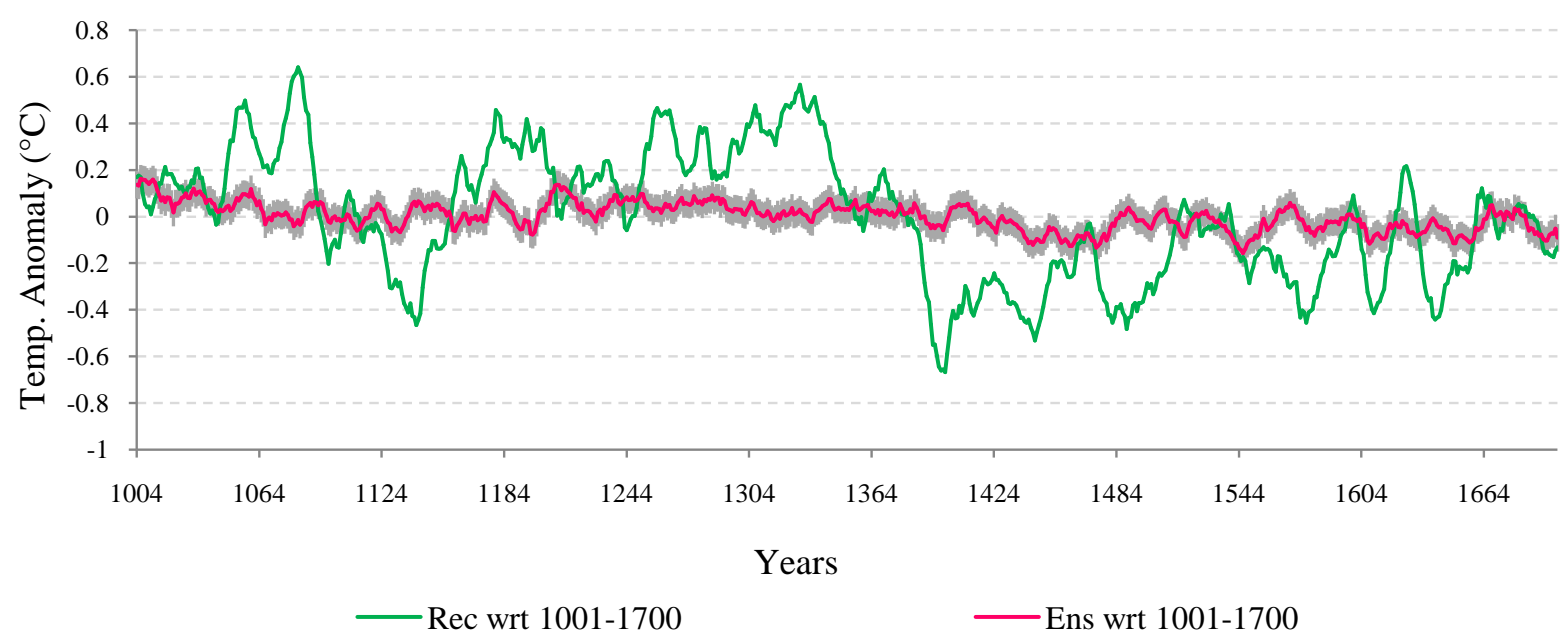

Figure 2. Temperature anomaly, 10-year moving averages, $1 \times$ forcing, summer for MCA and LIA. Green line corresponds to the reconstruction wrt 1001-1700 and pink line corresponds to the model 6-member mean wrt 1001-1700. Shaded area indicates the model standard deviation.

\section{1x winter wrt 1706-1800}



Rec wrt 1706-1800

Ens wrt 1706-1800

Figure 3. Temperature anomaly, 10-year moving averages, $1 \times$ forcing, winter. Pink line corresponds to the reconstruction wrt 1706-1800 and blue line corresponds to the model 6-member mean wrt 1706-1800. Shaded area indicates the model standard deviation. 
(figure not shown), with a mean difference between the two of approximately $0.2^{\circ} \mathrm{C}$, and maximum difference of $0.86^{\circ} \mathrm{C}$ in 1814 .

\section{Conclusions}

In this study, the South American temperature anomalies obtained with the GISS-ER model are compared to the temperature anomalies of Neukom reconstruction. The periods considered are 1001-1700 for summer with 1× and $2 \times$ solar forcing, that includes the MCA and LIA periods, and the period 1706-1800 for summer and winter with $1 \times$ and $2 \times$ forcing, that includes the pre-industrial period.

In general, the model 6-member mean is not very consistent with the reconstructions, since it displays very small interannual variability in contrast to what the reconstruction shows. Besides, the model often led to opposite sign anomalies in comparison to the reconstruction. The model anomalies that better reproduce the sign of the reconstruction is wrt 1001-1700 with $1 \times$ forcing for the summer season, with an error of only $33 \%$ of the comparisons.

The MCA and LIA are better reproduced by the model 6-member mean wrt 1001-1700 with $1 \times$ forcing for the summer, achieving an accuracy of the anomaly sign of almost 75\% for MCA and more than 73\% for LIA, when compared to the reconstructions.

From the analysis of temperature anomalies in South America, it can be concluded that the model represents better the reconstructions when the anomalies are larger. In spite of that, for the full period, the model overestimates the occurrence of positive anomalies in comparison to the reconstruction. It is also observed for summer that the 10-year moving averages worsen this problem for the shorter period (1706-1800), although it improves the accuracy in capturing the anomaly sign for the longer period (1001-1700).

It is important to emphasize that since Newkom reconstruction is based on proxy data; both internal and external forcing effects on the climate system are present. On the other hand, the model outputs employed in this study include only the solar forcing. Since the agreement obtained between model and reconstruction is only partial, it could be concluded that the solar forcing itself would not be the dominant one in the studied period. Therefore, in a future work the model response to other climate system forcings, as for example volcanic activity will be studied.

\section{Acknowledgements}

This work was performed at NASA-GISS with a fellowship granted by CONICET (Argentina) to the first author, who expresses gratitude to the supervisors Dr. Gavin Schmidt and Dr. Drew Shindell.

\section{References}

[1] Mann, M.E., et al. (2009) Global Signatures and Dynamical Origins of the Little Ice Age and Medieval Climate Anomaly. Science, 326, 1256-1260.

[2] Mann, M.E., Bradley, R.S. and Huges, M.K. (1998) Global-Scale Temperature Patterns and Climate Forcing over the Past Six Centuries. Nature, 392, 779-787. http://dx.doi.org/10.1038/33859

[3] Mann, et al. (2008) Proxy-Based Reconstructions of Hemispheric and Global Surface Temperature Variations over the Past Two Millennia. PNAS, 105, 13252-13257. http://dx.doi.org/10.1073/pnas.0805721105

[4] Jones, P.D., Osborn, T.J. and Brifa, K.R. (2001) The Evolution of Climate over the Last Millennium. Science, Paleoclimate Review, 292, 662-667.

[5] Briffa, K.R., et al. (1998) Influence of Volcanic Eruptions on Northern Hemisphere Summer Temperature over the Past 600 Years. Nature, 393, 450-455. http://dx.doi.org/10.1038/30943

[6] Briffa, K.R., et al. (2008) Trends in Recent Temperature and Radial Tree Growth Spanning 2000 Years across Northwest Eurasia. Philosophical Transactions of the Royal Society B, 363, 2271-2284. http://dx.doi.org/10.1098/rstb.2007.2199

[7] Cobb, et al. (2003) El Niño/Southern Oscillation and Tropical Pacific Climate during the Last Millennium. Nature, 424, 271-276. http://dx.doi.org/10.1038/nature01779

[8] Mann, M.E. and Jones, P.D. (2003) Global Surface Temperatures over the Past Two Millennia. Geophysical Research Letters, 30, 1820-1824. http://dx.doi.org/10.1029/2003GL017814

[9] Luterbacher, et al. (2004) European Seasonal and Annual Temperature Variability, Trends, and Extremes since 1500. Science, 303, 1499-1503. http://dx.doi.org/10.1126/science.1093877 
[10] Trouet, V., et al. (2009) Persistent Positive North Atlantic Oscillation Mode Dominated the Medieval Climate Anomaly. Science, 324, 78-80. http://dx.doi.org/10.1126/science.1166349

[11] Neukom, R., et al. (2010) Multiproxy Summer and Winter Surface Air Temperature Field Reconstructions for Southern South America Covering the Past Centuries. Climate Dynamics, 37, 35-51. http://dx.doi.org/10.1007/s00382-010-0793-3

[12] Neukom, R. and Gergis, J. (2012) Southern Hemisphere High-Resolution Palaeoclimate Records of the Last 2000 Years; Southern Hemisphere High Resolution Palaeoclimate Records of the Past 2000 Years. The Holocene, 5, 501-524. http://dx.doi.org/10.1177/0959683611427335

[13] Neukom, R. and Luterbacher, J. (2011) Climate Variability in the Southern Hemisphere. Global Change, 76, 26-29.

[14] Smerdon, J.E., et al. (2011) Spatial Performance of Four Climate Field Reconstruction Methods Targeting the Common Era. Geophysical Research Letters, 38, Article ID: L11705. http://dx.doi.org/10.1029/2011GL047372

[15] Bauer, E., Claussen, M., Brovkin, V. and Huenerbein, A. (2003) Assessing Climate Forcings of the Earth System for the Past Millennium. Geophysical Research Letters, 30, 1276-1284. http://dx.doi.org/10.1029/2002GL016639

[16] Intergovernmental Panel on Climate Change (IPCC) (2007) Climate Change. Cambridge.

[17] Luterbacher, et al. (2011) Reconstructed and Simulated Medieval Climate Anomaly in Southern South America. PAGES News, 19, 20-21.

[18] Schmidt, G.A., et al. (2006) Present-Day Atmospheric Simulations Using GISS Model E: Comparison to in Situ, Satellite, and Reanalysis Data. Journal of Climate, 19, 153-192. http://dx.doi.org/10.1175/JCLI3612.1

[19] Sun, S. and Bleck, R. (2006) Multi-Century Simulations with the Coupled GISS-HYCOM Climate Model: Control Experiments. Climate Dynamics, 26, 407-428. http://dx.doi.org/10.1007/s00382-005-0091-7

[20] Shindell, D.T., et al. (2006) Simulations of Preindustrial, Present-Day, and 2100 Conditions in the NASA GISS Composition and Climate Model G-PUCCINI. Atmospheric Chemistry and Physics, 6, 4427-4459. http://dx.doi.org/10.5194/acp-6-4427-2006

[21] Shindell, D.T., et al. (2006) Solar and Anthropogenic Forcing of Tropical Hydrology. Geophysical Research Letters, 33, Article ID: L24706. http://dx.doi.org/10.1029/2006GL027468

[22] Schmidt, G.A., Hoffmann, G., Shindell, D.T. and Hu, Y. (2005) Modeling Atmospheric Stable Water Isotopes and the Potential for Constraining Cloud Processes and Stratosphere-Troposphere Water Exchange. Journal of Geophysical Research, 110, Article ID: 021314. http://dx.doi.org/10.1029/2005JD005790

[23] Lean, J.L., Wang, Y.-M. and Sheeley Jr., N.R. (2002) The Effect of Increasing Solar Activity on the Sun’s Total and Open Magnetic Flux during Multiple Cycles: Implications for Solar Forcing of Climate. Geophysical Research Letters, 29, 77-1-77-2.

[24] Bard, E., Raisbeck, G., Yiou, F. and Jouzel, J. (2007) Comment on "Solar Activity during the Last 1000 yr Inferred from Radionuclide Records” by Muscheler et al. (2007). Quaternary Science Reviews, 26, 2301-2304. http://dx.doi.org/10.1016/j.quascirev.2007.06.002

[25] Beckman, J.E. and Mahoney, T.J. (1998) The Maunder Minimum and Climate Change: Have Historical Records Aided Current Research? ASP Conference Series, 153, 212-217. 
Scientific Research Publishing (SCIRP) is one of the largest Open Access journal publishers. It is currently publishing more than 200 open access, online, peer-reviewed journals covering a wide range of academic disciplines. SCIRP serves the worldwide academic communities and contributes to the progress and application of science with its publication.

Other selected journals from SCIRP are listed as below. Submit your manuscript to us via either submit@scirp.org or Online Submission Portal.
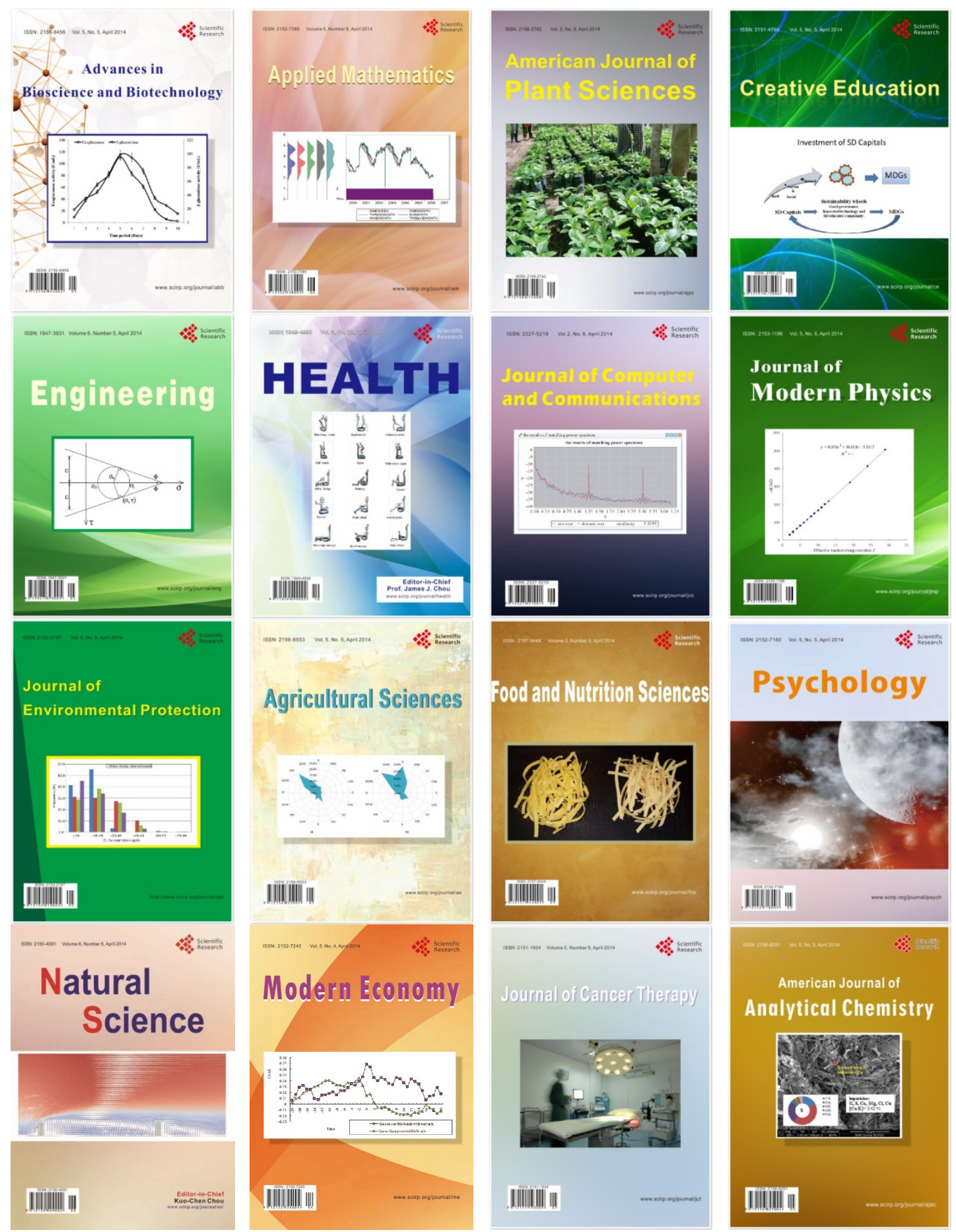